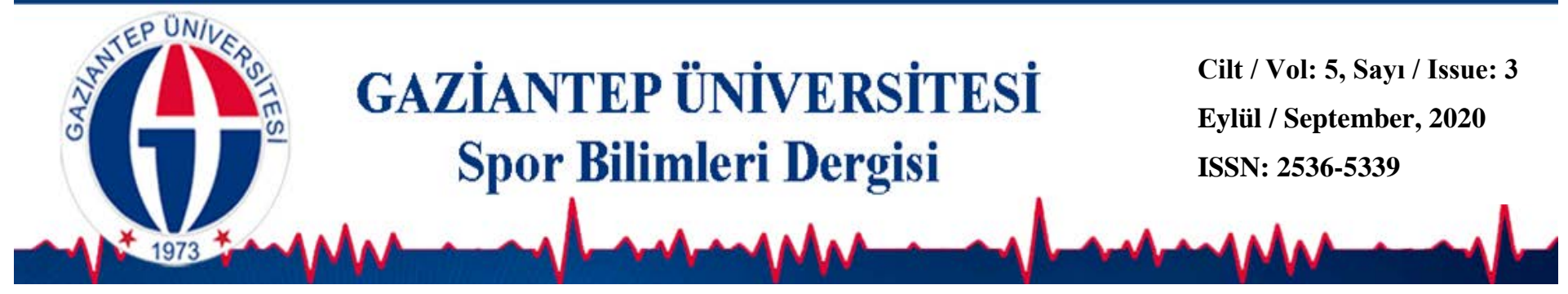

\title{
Spor Bilimleri Fakültesi Öğrencilerinin Gelecek Zaman Algı Düzeylerinin İncelenmesi
}

\author{
Metin YILDIZ ${ }^{1 *}(\mathbb{D}$ \\ Tuba ŞEKERCi ${ }^{2}$ \\ Abdurrahman KIRTEPE ${ }^{3}$ (i) \\ ${ }^{1}$ Gençlik Spor İl Müdürlüğü, ELAZIĞ

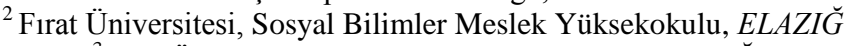 \\ ${ }^{3}$ Frrat Üniversitesi Spor Bilimleri Fakültesi, $E L A Z I \breve{G}$
}

DOI: $10.31680 / g a u n j s s .724694$

Orijinal Makale / Original Article

Geliş Tarihi / Received: 31.05.2020～Kabul Tarihi / Accepted: 13.08.2020Ｙayın Tarihi / Published: 14.09.2020

\begin{abstract}
Öz
Üniversite eğitimi yıllar boyu süren bir süreci kapsamaktadır. Araştırmanın amacını spor bilimlerinde okuyan öğrencilerin gelecek zaman algılarının farklı değişkenlere göre incelenmesi oluşturmuştur. Araştırmaya Fırat Üniversitesi Spor Bilimleri Fakültesinde öğrenim gören 247 öğrenci katıımıştır. Çalışmada katıım sağlayanların gelecek zaman algı puanlarını belirlemek amacıyla Husman ve Shell (1996) tarafınca geliştirilen ayrıca Türkçe' ye uyarlaması, geçerlik ve güvenirlik çalışması Avcı ve Erden (2009) tarafınca gerçekleştirilen Gelecek Zaman Algısı Ölçeği (GZAÖ) kullanılmıştır. Çalışmada katıım sağlayanların sosyo-demografik bilgilerinin dağılımlarını belirlemek amacıyla; tanımlayıcı istatistikleri, anlamlı farklııkların belirlemek amacıyla ise Kruskal Wallis ve MannWhitney $U$ testlerinden faydalanılmıştır. Araştırmada öğrencilerin cinsiyeti ile gelecek zaman algı düzeyleri arasında anlamlı bir farklılaşma olduğu görülmüşken, öğrencilerin yaş ve spor yapma durumları ile gelecek zaman algıları arasında bir farklılaşma görülmemiştir. Sonuçta, erkek öğrencilerin kız öğrencilere göre yapacakları bir işi son güne ya da son ana bırakmadıkları ve bu konuda kız öğrencilere göre sorumluluk duygularının daha fazla olduğu, öğrencilerin yaşlarına bakılmaksızın kendilerine yakın ya da uzak gelecekte bir hedef belirledikleri, öğrencilerin gelecek zaman ile ilgili bir plan yapmalarında düzenli spor yapmalarının herhangi bir etkisinin olmadığı görülmüştür.
\end{abstract}

Anahtar Kelimeler: Öğrenci, gelecek zaman, üniversite

\section{Investigation Of Future Perception Levels of Faculty of Sport Sciences Students}

\begin{abstract}
University education includes a process which continues for years. This research aims to analyze the students' perceptions of future time according to different variables who study at sport sciences.247 students participated this research who study at Fırat University Sport Science Faculty.To determine the future time perception score of the participants of this research, Future Time Perception Scale (GZAÖ) which is developed by Husman and Shell (1996) and of which adaptation to Turkish and study of validity and reliability was carried by Avcı and Erden (2009) was used .In this research ,to determine the participants' distrubition information of socio-demographic , definitive statistics were used and to determine the statistically significant differences Kruskal Wallis and MannWhitney $U$ Tests were used.In this research, statistically significant differences were seen between students gender and future time perception level but statistically significant differences weren't seen between students age, doing sport case and future time perception. As a result, It is seen that male students do not leave their duties to the last minute unlike female students. Male students' sense of responsibility is higher than female students for this subject.It is also seen that students determined an aim for near or distant future regardless of their age.An impact between students doing sport case and making plans for future time was not seen.
\end{abstract}

Key Words: Student, future time, university

\footnotetext{
* Sorumlu Yazar: Metin YILDIZ
}

E-mail: metinyildiz.2323@gmail.com 


\section{Giriş}

İnsanların bilimsel bakış açıları değişiklik göstermesinden dolayı zamanın literatürde farklı tanımları yapılmaktadır. İnsanın duyu organları ile fark edemediği psikolojik, sosyolojik, fiziksel ve felsefi boyutları olan bir olgu ve gerçekliğe zaman denir (Güven ve Yeşil, 2011). Tutar (2007) ve Tengilimoğlu (2003) ise zamanı; olayların geçmişten günümüze varıp, geleceğe doğru birbirini izleyen kesintisi olmayan bir süreç olup, hareketi anlamlandıran ana unsur olarak tanımlamışlardır.

Geçmiş zaman, şimdiki zaman ve gelecek zaman şeklinde isimlendirilen farklı zaman kalıpları kişilerin deneyimlerini anlamlandırmalarında önemli derecede tesirlidir (Zimbardo ve Boyd, 1999). Geçmiş ve gelecek kavramları ne kadar da aralarında bir bağlantı olduğu düşünülse de, geçmiş olgusu zaten bilinmektedir ancak geleceği bilmek imkânsızdır (Hazzlett, 2011).

Her bireyin, kendi geleceğine dair hedeflediği amaçların zamansal olarak mesafesi birbirinden farklıdır. Kimi insanlar, uzun vadeli plan yaparken bazı insanlar ise kısa vadeli plan yapmaktadırlar (Nuttin ve Lens, 1985). Gelecek zaman algısı bireyin, kısa ya da uzun gelecek dilimlerindeki beklentilerinin, amaçlarının şu anki davranışları üzerine etkisi olarak tanımlanmaktadır (Simons ve ark., 2004; Avcı ve Erden, 2013).

Gelecek zaman algısı kişinin, yakın yada uzak gelecek zaman beklentilerinin, amaçlarının mevcut eylemleri üzerine etkisi olarak tanımlanmaktadır (Simons ve ark., 2004; Avcı ve Erden, 2013). Hayatın her devresinde süreklilik arz eden bir davranış değiştirme ve geliştirme sürecine eğitim denir. Bu sürecin eğitim kurumlarında yürütülen kısmı; amaç, içerik, yöntem ve teknikle, değerlendirme basamaklarından oluşur (Deniz ve ark., 2006).

Eğitimin şüphesiz ki gelecek zaman algısına doğrudan etkisi vardır. Atasoy (2012)'a göre gelecek zaman algısı ve başarı güdülemesi arasındaki pozitif yönde bir ilişki vardır. Buna göre; öğrencilerin geleceğe ilişkin algıları onların inançlarını, öğrenmeye karşı güdülenmelerini etkileyerek başarıları üzerinde olumlu bir etki yaratır. Gelecek zaman algısı ile eğitim arasında ki ilişki araştırmacıların dikkatini çekmiştir (Bembenutty ve Karabenick, 2004; Phalet ve ark., 2004).

Üniversite öğren hayatı, yıllarca devam edecek davranış şekillerinin meydana geldiği en hayati süreçtir (Zorba ve ark., 2013). Üniversitede eğitim alan bireyleri, gelecek hayatlarına dair hazırlık yapmanın önemi üzerinde duran ebeveynleri ve bu bireyler öğretmenlerince belirlenen çokça görev ve beklenti ile yüzleşmekte ve bu 
beklentiler bu bireylerin ileriki hayatlarını, planlarını ve imkânlarını etkilemektedir (Çalışkan, 2004).

Bu kapsamda spor bilimlerinde okuyan öğrencilerin gelecek zaman algılarının farklı değişkenlere göre incelenmesi bu çalışmanın amacını oluşturmuştur.

\section{Gereç ve Yöntem}

Spor bilimleri fakültesi öğrencilerinin gelecek zaman algılarını incelemek amacıyla yapılan bu çalışmada kullanılan yöntem ve araçlar aşağıda verilmiştir.

\section{Araştırma Deseni}

Çalışmada nicel araştırma yöntemlerinden kesitsel (crosssectional) yöntem kullanılmıştır. Kullanılan yöntem spor bilimleri ile sosyal bilimler alanlarında sık olarak yararlanılan bir yöntemdir. Bu yöntemde örneklem grubundan anket yâda ölçek vasıtası ile elde edilen veri çeşitli ilişkilerin açıklanmasında kullanılır ve evrene genellenir (Gratton ve Jones, 2010).

\section{Veri Toplama Araçları}

Çalışmada araştırmacılar tarafından katılımcıların cinsiyet, yaş ve düzenli olarak spor yapıp yapmadıklarını ölçmeye yönelik kişisel bilgi formu oluşturulmuştur.

Gelecek zaman Algısı Ölçeği: Çalışma katılımcıların gelecek zaman algı durumlarını belirlemek için Husman ile Shell (1996) tarafınca geliştirilen Türkçe' ye uyarlaması ile geçerlik, güvenirlik analizleri ise Avcı ve Erden (2009) tarafından gerçekleştirilen Gelecek Zaman Algısı Ölçeği (GZAÖ) kullanılmıştır. Ölçek, 27 maddeden oluşmaktadır ve 5' li likert tipi ölçek üzerinden değerlendirilmektedir. Ölçeğin, hız (3 Madde), genişlik (5 Madde), değer (7 madde) ve bağlılık (12 madde), şeklinde dört alt boyutu bulunmaktadır. Bütün alt boyutlardan ulaşılan puan 1-5 arasındadır. Ölçeğin alt boyutlardan ulaşılan puanların fazlalığı, katılımcının alt boyut ile ölçülen özelliğe sahipliğinin fazlalaştığını göstermektedir.

\section{Araştırma Grubu}

Çalışmanın örneklemini 2019-2020 eğitim-öğretim yılı Fırat Üniversitesi spor bilimleri fakültesinde öğrenim gören 166'sı erkek 81 'i kadın, toplam 247 öğrenci oluşturmuştur. 


\section{Verilerin Analizi}

Öncelikle uygulanan ölçeğin örneklem grubu için güvenilirliğini tespit etmek için Cronbach alfa iç tutarlılık katsayısına bakıldı. Buna göre toplam ölçek için hesaplanan toplam iç tutarlık katsayısı .704 olarak hesaplanmıştır. Devamında verilerin nasıl dağıldığının belirlenmesi için tek örneklem Kolmogorov-Smirnov ve Shapiro-wilk testleri uygulanıp, basıklık ve çarpıklık değerlerine bakılmıştır ve verilerin normal dağılım göstermediği tespit edilmiştir (Sig.=.005). Çalışmaya katılım sağlayanların sosyo-demografik bilgilerinin dağılımlarının belirlenmesi için tanımlayıcı istatistikleri, anlamlı farklılıkların belirlenmesi için ise Mann-Whitney $U$ testi ve Kruskal Wallis testinden faydalanılmıştır.

\section{Bulgular}

Tablo1. Cinsiyete Göre Gelecek Zaman Algısı

\begin{tabular}{lllllll}
\hline Alt Boyut & Cinsiyet & $\mathbf{N}$ & Sıra ort.. & Sıra Top. & U & P \\
\hline Bağlıık & Kadın & 81 & 115,91 & 9388,50 & 6067,500 & .21 \\
& Erkek & 166 & 127,95 & 21239,50 & & \\
Değer & Kadın & 81 & 114,88 & 9305,00 & 5984,000 & .16 \\
& Erkek & 166 & 128,45 & 21323,00 & & \\
Hız & Kadın & 81 & 104,81 & 8489,50 & 5168,500 & .00 \\
\multirow{2}{*}{ Genişlik } & Erkek & 166 & 133,36 & 22138,50 & & \\
& Kadın & 81 & 117,16 & 9490,00 & 6169,000 & .29 \\
& Erkek & 166 & 127,34 & 21138,00 & & \\
\hline
\end{tabular}

Katılımcıların cinsiyetleri ile ölçeğin bağlıık, ,değer ve genişlik alt boyutları arasında anlamlı bir farklılaşma görülmemiştir ( $p>0,05)$. Ölçeğin hız alt boyutunda ise erkeklerin puan ortalamasının kadınlardan daha yüksek ve erkek katılımcıların lehine istatistiksel olarak anlamlı farklılaşma olduğu görülmüştür $(p<0,05)$.

Tablo 2. Yaşa Göre Gelecek Zaman Algısı

\begin{tabular}{|c|c|c|c|c|c|c|}
\hline Alt Boyut & Yaş & $\mathbf{N}$ & Sıra ort.. & $\begin{array}{l}\text { Serbestlik } \\
\text { derecesi }\end{array}$ & $x^{2}$ & $\mathbf{P}$ \\
\hline \multirow[t]{4}{*}{ Bağlılık } & $17-20$ & 91 & 134,19 & & & \\
\hline & $21-25$ & 130 & 118,13 & 3 & 2,94 & .40 \\
\hline & $26-29$ & 15 & 117,43 & & & \\
\hline & 30 ve üzeri & 11 & 118,05 & & & \\
\hline \multirow[t]{4}{*}{ Değer } & $17-20$ & 91 & 139,90 & & & \\
\hline & $21-25$ & 130 & 116,22 & 3 & 14,02 & .00 \\
\hline & $26-29$ & 15 & 137,80 & & & \\
\hline & 30 ve üzeri & 11 & 65,59 & & & \\
\hline \multirow[t]{4}{*}{ Hız } & $17-20$ & 91 & 132,95 & & & \\
\hline & $21-25$ & 130 & 117,56 & 3 & 2,58 & ,46 \\
\hline & $26-29$ & 15 & 121,73 & & & \\
\hline & 30 ve üzeri & 11 & 129,18 & & & \\
\hline \multirow[t]{4}{*}{ Genişlik } & $17-20$ & 91 & 129,22 & & & \\
\hline & $21-25$ & 130 & 121,63 & 3 & ,91 & .82 \\
\hline & $26-29$ & 15 & 120,70 & & & \\
\hline & 30 ve üzeri & 11 & 113,32 & & & \\
\hline
\end{tabular}


Katılımcıların yaşlarına göre gelecek zaman algılarıyla ölçeğin değer alt boyutu arasında anlamlı bir farklılık olduğu $(p<0,05)$ tespit edilmiştir. Ölçeğin diğer alt boyutları ile katılımcıların yaş parametreleri arasında ise anlamlı düzeyde farklılaşma görülmemiştir $(p>0,05)$.

Tablo 3. Düzenli Spor Yapma Durumuna Göre Gelecek Zaman Algısı

\begin{tabular}{lllllll}
\hline Alt Boyut & $\begin{array}{l}\text { Düzenli } \\
\text { olarak spor } \\
\text { yapma } \\
\text { durumu }\end{array}$ & $\mathbf{N}$ & Sıra ort.. & Sıra Top. & $\mathbf{U}$ & $\mathbf{P}$ \\
\hline Bağlılık & Evet & 81 & 123,70 & 18678,50 & 6689,500 & .62 \\
& Hayır & 166 & 119,21 & 10967,50 & & \\
Değer & Evet & 81 & 126,64 & 19123,00 & 6245,000 & .18 \\
& Hayır & 166 & 114,38 & 10523,00 & & \\
Hız & Evet & 81 & 122,90 & 18558,50 & 6809,500 & .79 \\
Genişlik & Hayır & 166 & 120,52 & 11087,50 & & .16 \\
& Evet & 81 & 126,90 & 19162,00 & 6206,000 & .16 \\
\hline
\end{tabular}

Katıımcıların düzenli spor yapma durumları ile gelecek zaman algılarıyla ölçeğin alt boyutları arasında istatistiksel olarak anlamlı bir farklılaşma görülmemiştir $(p>0,05)$.

\section{Tartışma ve Sonuç}

Katıımcıların cinsiyete göre gelecek zaman algılarının hız alt boyutunda erkek katıımcıların kadın katılımcılara oranla daha yüksek puana sahip oldukları ayrıca erkeklerin lehine anlamlı bir farklılaşma olduğu görülmüştür. Husman ve Shell (2008)'e göre hız, kişinin yapması gereken görevlerini sona bırakmayıp, zamanında icra etmesiyle ilgili bir konudur. Demirel ve ark. (2016) yaptıkları çalışmada cinsiyet ile ölçeğin hız alt boyutu arasında anlamlı bir farklılaşma tespit etmemişlerdir. Çalışma bu yönüyle araştırmamızla zıtıı göstermektedir. Bu durumun katılımcıların farkı üniversitelerden olmasından ve kişisel tercihlerden kaynaklandığı düşünülmektedir.

Öğrencilerin yaşları ile gelecek zaman algıları ölçeğin değer alt boyutu arasında anlamlı bir farklılık olduğu görülmüştür. Kişinin yakın veya uzak gelecekte erişmek istediği amaçlara verdiği önem değer olarak ifade edilmektedir (Gjesme, 1975). Nurmi (1991) de yapmış olduğu araştırma sonucunda yaşın gelecek zaman algısına etkisinin olduğunu belirtmiştir. Çalışma araştırmamızın hız alt boyutu ile yaş arasında anlamlı farklılık çıkması yönüyle aynı doğrultuda sonuç vermiştir.

Öğrencilerin düzenli spor yapma durumu ile gelecek zaman algıları arasında istatistiksel olarak bir farklılaşma görülmemiştir. Yapılan çalışmada öğrencilerin 
gelecek zaman algıları düzenli olarak spor yapma durumlarına göre düzenli olarak spor yapan öğrencilerin lehinde bağlılık alt boyutunda anlamlı farklılık görülmüştür. (Demirel ve ark., 2016). Çalışma, araştırmamızın bağıılık alt boyutuyla farklı yönde sonuç vermiştir.

Sonuç olarak; Spor bilimleri fakültesinde okuyan erkek öğrencilerin kız öğrencilere göre yapacakları bir işi son güne ya da son ana bırakmadıkları ve bu konuda kız öğrencilere göre sorumluluk duygularının daha fazla olduğu görülmüştür. Öğrencilerin yaşlarına bakılmaksızın kendilerine yakın ya da uzak gelecekte bir hedef belirledikleri ve o hedef yolunda ilerledikleri belirlenmiştir. Öğrencilerin gelecek zaman ile ilgili bir plan yapmalarında düzenli spor yapmalarının herhangi bir etkisinin olmadığı görülmüştür. Bu sonuç ayrıca üzerinde düşünülmesi ve farklı bir çalışmayla ortaya konulması gereken bulgular arasındadır.

Bu çalışmanın sadece bir üniversite ile sınırlı olması nedeniyle farklı sonuçlar elde edilmesi açısından daha fazla üniversitede ve farklı bölümlerde okuyan öğrencileri üzerinde yapılması gerektiği düşünülmektedir. Yapılan araştırmalarda beden eğitimi ve spor yüksekokullarından mezun öğrencilerin gerek kamu gerekse özel sektörde iş bulma imkânlarını düşük olarak gördüklerini belirtmişlerdir (Yıldız ve Tüfekçioğlu, 2008). Ülkemizin ileride sportif geleceğinin belirlenmesi ve yön verilmesi bakımında spor bilimlerinden mezun olan öğrencilerin daha fazla iş imkânına sahip olması ve geleceğe dair daha iyi planlama yapmalarının önem arz ettiği düşünülmektedir.

\section{Kaynaklar}

Atasoy, S. (2012). Farklı yaş gruplarının merkezi sınavlara hazırlanma sürecindeki durumluk kaygı düzeyleri ve gelecek zaman perspektiflerinin karşılaştırılması. Maltepe Üniversitesi Sosyal Bilimler Enstitüsü, Yüksek Lisans Tezi.

Avcı, S. \& Erden M. (2009). Gelecek zaman algısı ölçeği'nin Türkçe formunun geçerlik ve güvenirlik çalışması. Çukurova Üniversitesi Eğitim Fakültesi Dergisi, 3(37), 1-12.

Avcı,S. \& Erden,M. (2013).Gelecek zaman algısı ve akademik alanda arzuların ertelenmesinin öğretmen adaylarının akademik başarıları üzerindeki etkisi. Ahi Evran Üniversitesi Kırşehir Eğitim Fakültesi Dergisi, 14(1), 389-406.

Bembenutty, H., \& Karabenick, S. A. (2004). In herent association between academic delay of gratification, future time perspective, and self-regulated learning. Educational psychology review, 16(1), 35-57. 
Çalışkan, E.A. (2004). Milli eğitimi geliştirme projesine bağlı okullardaki öğrencilerin gelecek zaman perspektifleri üzerine bir araştırma. Uludağ Üniversitesi, Sosyal Bilimler Enstitüsü, Yüksek Lisans Tezi.

Demirel, M., Işık, U., Demirel, D. H., Üstün, Ü. D., \& Gümüşgül, O. (2016). Gelecek zaman algısı: Beden eğitimi ve spor yüksekokulu öğrencilerine yönelik bir çalışma. İstanbul Üniversitesi Spor Bilimleri Dergisi, 6(1), 10-20.

Deniz, M., Avşaroğlu, S. \& Fidan Ö. (2006). İngilizce öğretmenlerinin öğrencileri motive etme düzeylerinin incelenmesi. İnönü Üniversitesi Eğitim Fakültesi Dergisi,7(11), 61-73.

Gjesme, T. (1975). Slope of gradients for performance as a function of achievement motive, goaldistance in time, and future time orientation. The Journal of Psychology, 91, 143-160.

Gratton, C. \& Jones, I. (2010). Research methods for sport studies. Second Edition, Routledge, London.

Güven, M. ve Yeşil, S. (2011). İşletmelerde Zaman Yönetimi, (Editör: İ. Bakan), 2. Baskı, Çağdaş Yönetim Yaklaşımları İlkeler, Kavramlar ve Yaklaşımlar, s:60,Beta Basım A.Ş., İstanbul.

Hazlett, A. (2011). How the past depends on the future. Blackwell Publishing Ltd Ratio (newseries), 24, 167-175.

Husman, J.E. \& Shell, D.F. (1996). Beliefs and perceptions about the future: A conceptualization and measurement of future time perspective. 26TH International Congress of Psychology, Montreal, Canada.

Husman, J., \& Shell, D. F. (2008). Beliefs and perceptions about the future: A measurement of future time perspective. Learning and individual differences, 18(2), 166-175.

Nurmi, J.E. (1991). How do adolescents see their future? A review of the development of future orientation and planning. Developmental review, 11(1), 159.

Nuttin, J. Ve Lens,W. (1985). Future Time Perspective and Motivation: Theory and Research Method. Belgium: Lawrence Erlbaum Associates.

Phalet, K., Andriessen, I. ve Lens, W. (2004). How futuregoal senhance motivation and learning in multicultural classrooms. Educational Psychology Review, 16(1), 59-89. 
Simons,J.,Vansteenkiste, M., Lens,W. ve Lacante,M. (2004). Placing motivation and future time perspective theory in a temporal perspective. Educational Psychology Review, 16(2), 121-139.

Tengilimoğlu, D., Tutar, H., Altınöz, M., Başpınar, N. Ö, \& Erdönmez, C. (2003). Zaman Yönetimi, ( Editör: Hasan Tutar)Ankara: Nobel Yayın Dağıtım. Ankara Tutar, H. (2007). Zaman Yönetimi. II. Baskı, Seçkin yayıncılık San ve Tic. AŞ, Sözkesen Matbaacılık, Ankara.

Yıldız, S. M., \& Tüfekçioğlu, E. (2008). Beden Eğitimi Ve Spor Yüksekokullarında Eğitim Destekleri, Kariyer Gelişim Olanakları Ve Eğitim Sonrasında İstihdam Durumunun İncelenmesi. Beden Eğitimi ve Spor Bilimleri Dergisi, 2(2), 89-97.

Zimbardo, P.G. \& Boyd, J.N. (1999). Putting time in perspective: A valid, reliable Individual differences-metric. Journal of Personality and Social Psychology, 77 (6), 1271-1288.

Zorba, E., Cerit, E., Gümüşdağ, H., \& Evli, M. (2013). Rekreasyon bölümlerinin tercih edilme nedenleri ve bölüm öğrencilerinin beklentilerinin araştıııması. Uluslararası Hakemli Akademik Spor Sağlık ve Tıp Bilimleri Dergisi, 8(3), 1-15. 